\title{
Review of Postpartum Contraceptive Practices at Chiang Mai University Hospital: Implications for Improving Quality of Service
}

\author{
Somsak Chaovisitsaree Supranee Noi-um Chumnan Kietpeerakool \\ Department of Obstetrics and Gynecology, Faculty of Medicine, Chiang Mai University, Chiang Mai, Thailand
}

\section{Key Words}

Postpartum contraception · Family planning $\cdot$ Long-acting reversible contraception $\cdot$ Compliance

\begin{abstract}
Objective: To evaluate the acceptance rate and patterns of contraceptive use among postpartum women. Subjects and Methods: The records of 1,009 postpartum women attending the Family Planning Clinic at Chiang Mai University Hospital, Thailand, during January to December 2009 were reviewed. Results: Mean age was $28.2 \pm 5.7$ years (range 15-48). Almost all 920 women (91.2\%) practiced breastfeeding. The acceptance rate of contraception was $97.6 \%$. The types of contraceptive used were: depot medroxyprogesterone acetate, 387 (38.4\%); progestin-only pills, 262 (26.0\%); tubal resection, 201 (19.9\%); male condom, 78 (7.7\%); oral combined pills, 49 (4.9\%); intrauterine device, 5 (0.5\%); implant, 3 (0.3\%). Among women undergoing tubal resection, 29 (14.4\%) were $\leq 24$ years of age. Significant independent predictors for using long-acting reversible contraception were young age and little or no formal education. Conclusion: The acceptance rate of contraception in this study was high. However, the following issues need to be evaluated: compliance of women using progestin-only pills, awareness of long-acting reversible contraception as
\end{abstract}

an alternative option in women considering sterilization, and interventions to promote the use of intrauterine devices and implants.

Copyright $\odot 2011$ S. Karger AG, Basel

\section{Introduction}

The unacceptably high incidence rates of maternal mortality and stillbirth in developing countries have been consistently reported over the past several decades and remain an unsolved issue today [1]. Besides the lack of resources and well-trained health professionals, other factors that contribute to these poor obstetrics outcomes are unintended pregnancy, particularly short interpregnancy intervals, high parity, and pregnancy in high-risk groups, including teenagers, elderly women, and those with concomitant medical illness [2-4]. Effective family planning services for avoiding or spacing future pregnancies is a key to reducing mortality and morbidity among women and children in developing countries [5].

Postpartum visits are an ideal time to discuss and implement appropriate family planning services. At this time, women and their husbands are highly motivated and are receptive to counseling about family planning practices and existing choices of contraception. 
The Family Planning Clinic at Chiang Mai University Hospital Thailand serves approximately 1,000 postpartum women annually. If an effective family planning service is to be developed, evaluation of routine practices is required. This study was accordingly undertaken to evaluate the acceptance rate and patterns of contraceptive use among postpartum women. The results of this study would be helpful in establishing proper management protocol and identifying areas of family planning services that need to be improved.

\section{Subjects and Methods}

The Research Ethics Committee of the Faculty of Medicine approved this study. The records of all postpartum women attending the Family Planning Clinic at Chiang Mai University Hospital from January to December 2009 were reviewed. Abstracted data included baseline demographic characteristics, breastfeeding practice, and acceptance rate and types of contraception used.

At Chiang Mai University Hospital, couples are scheduled at 6 weeks after delivery for postpartum evaluations and family planning counseling. During this time, women are advised to avoid sexual intercourse.

The main providers responsible for family planning counseling are obstetrics and gynecological trainees and registered nurses under supervision of the staff. Counseling includes informing and discussing with the women and their husbands about all of the available contraceptive methods, and suggesting the most appropriate methods.

Statistical analyses were carried out using SPSS for Windows version 17 (SPSS, Chicago, Ill., USA). Logistic regression analysis was used to estimate adjusted odds ratio and 95\% confidence interval (CI) to examine the association between variables associated with $\mathrm{p}<0.20$ in univariate analyses and the outcome of interest.

\section{Results}

During the study period, 1,009 postpartum women attended the Family Planning Clinic, Chiang Mai University Hospital. Mean age was $28.2 \pm 5.7$ years (range $15-$ 48). Among the 1,009 women, $281(27.8 \%)$ were $\leq 24$ years of age and $22(2.2 \%)$ were $>40$ years of age.

The majority of women $(768,76.1 \%)$ had delivered vaginally and $102(10.1 \%)$ had history of preterm delivery for this most recent pregnancy. The median number of living children was 1.0 (interquartile range, $1-2) ; 8$ (0.8\%) women had no living child; 55 (5.5\%) had 3 or more living children. Almost all $(920,91.2 \%)$ of the women practiced breastfeeding.
$136(13.5 \%)$ women admitted having vaginal sexual intercourse before attending the postpartum clinic and 18 women did not utilize any contraceptive protection.

The overall acceptance rate of postpartum contraception was $97.6 \%$ (985 women). The types of contraceptive used were: depot medroxyprogesterone acetate (DMPA), 387 (38.4\%); progestin-only pills (POPs), 262 (26.0\%); tubal resection, 201 (19.9\%); male condom, 78 (7.7\%); oral combined pills (OCPs), 49 (4.9\%); intrauterine device (IUD), 5 (0.5\%); implant, 3 (0.3\%). Among 201 tubal resection procedures, 79 were performed during cesarean section.

The types of contraceptive use cross-tabulated with baseline demographic characteristics are given in table 1 . The use of DMPA was the most common method across all different groups except for women with 3 or more living children and women aged $>40$ years. Tubal resection was the most common method in those 2 groups.

After excluding women who did not use any contraception and women who had undergone sterilization $(\mathrm{n}=225)$, the acceptance rate of long-acting reversible contraception (LARC) including DMPA, IUD, and implant in the remaining 784 women was $50.4 \%$ (95\% CI, 46.8-53.9\%). Almost all the women 387 (97.9\%) in the LARC group used DMPA.

Independent predictors for using LARC are given in table 2. Four variables including age, ethnicity, education level, and number of living children had a $\mathrm{p}$ value of $<0.20$. Significant independent predictors of using LARC were young age (adjusted OR, 1.74; 95\% CI, 1.28-2.37) and little or no formal education (adjusted OR, 1.85, 95\% CI, 1.29-2.66) (table 2).

\section{Discussion}

The variation in postpartum contraceptive practices seen in this study confirmed previous studies [6-9]. The variety of contraceptive methods used is related to various differences in baseline characteristics, details of intended fertility spacing, completeness of the family, and attitude and beliefs of either the women or care providers in individual institution. Overall, the acceptance rate of contraception in the present study was high (98\%).

The $26.0 \%$ acceptance rate of POPs in this study was considerably high compared to existing reports $[6,7]$. Although POPs would be ideal in breastfeeding mothers, this method generally requires a high level of the woman's cooperation and compliance [10]. In addition, it should be noted that the high rate of early discontinuation of 
Table 1. Contraceptive used stratified by baseline demographic characteristics of the 1,009 women

\begin{tabular}{|c|c|c|c|c|c|c|c|c|c|c|}
\hline \multirow[t]{2}{*}{ Variables } & \multirow[t]{2}{*}{ Category } & \multicolumn{9}{|c|}{ Contraceptive use } \\
\hline & & none & OCP & POP & condom & DMPA & implant & IUD & $\mathrm{TR}$ & total \\
\hline \multirow[t]{5}{*}{ Age } & $\leq 24$ years & $5(1.8)$ & $18(6.4)$ & $73(25.9)$ & $8(2.8)$ & $148(52.7)$ & $0(0)$ & $0(0)$ & $29(10.3)$ & $281(100)$ \\
\hline & $25-30$ years & $9(2.3)$ & $21(5.3)$ & $118(29.8)$ & $42(10.6)$ & $148(37.2)$ & $1(0.3)$ & $3(0.8)$ & $56(14.1)$ & $398(100)$ \\
\hline & $31-35$ years & $7(3.3)$ & $9(4.3)$ & $49(23.4)$ & $19(9.1)$ & $62(29.7)$ & $1(0.5)$ & $2(0.9)$ & $60(28.7)$ & 209 (100) \\
\hline & $36-40$ years & $3(3.0)$ & $1(1.0)$ & $18(18.2)$ & $9(9.1)$ & $25(25.3)$ & $1(1.0)$ & $0(0)$ & $42(42.4)$ & $99(100)$ \\
\hline & $>40$ years & $0(0)$ & $0(0)$ & $4(18.2)$ & $0(0)$ & $4(18.2)$ & $0(0)$ & $0(0)$ & $14(63.6)$ & $22(100)$ \\
\hline \multirow[t]{2}{*}{ Ethnicity } & Thai & $21(2.3)$ & $48(5.3)$ & $236(26.0)$ & $73(8.0)$ & $331(36.4)$ & $3(0.3)$ & $4(0.4)$ & $193(21.2)$ & $909(100)$ \\
\hline & Minority $^{\mathrm{a}}$ & $3(3.0)$ & $1(1.0)$ & $26(26.0)$ & $5(5.0)$ & $56(56.0)$ & $0(0)$ & $1(1.0)$ & $8(8.0)$ & $100(100)$ \\
\hline \multirow[t]{3}{*}{ Education } & No & $1(1.1)$ & $1(1.1)$ & $27(28.7)$ & $3(3.2)$ & $53(56.4)$ & $0(0)$ & $1(1.1)$ & $8(8.5)$ & $94(100)$ \\
\hline & PS & $2(1.8)$ & $4(3.6)$ & $17(15.2)$ & $7(6.3)$ & $45(40.2)$ & $0(0)$ & $0(0)$ & $37(33.3)$ & $112(100)$ \\
\hline & Higher & $21(2.6)$ & $44(5.5)$ & $218(27.1)$ & $68(8.5)$ & $289(36.0)$ & $3(0.4)$ & $4(0.5)$ & $156(19.4)$ & $803(100)$ \\
\hline & 0 & $0(0)$ & $7(87.5)$ & $0(0)$ & $1(12.5)$ & $0(0)$ & $0(0)$ & $0(0)$ & $0(0)$ & $8(100)$ \\
\hline \multirow{2}{*}{ children } & $1-2$ & $22(2.3)$ & $41(4.3)$ & $259(27.4)$ & $74(7.8)$ & $374(39.5)$ & $3(0.3)$ & $5(0.5)$ & $168(17.8)$ & $946(100)$ \\
\hline & $\geq 3$ & $2(3.6)$ & $1(1.8)$ & $3(5.5)$ & $3(5.5)$ & $13(23.6)$ & $0(0)$ & $0(0)$ & $33(60.0)$ & $55(100)$ \\
\hline
\end{tabular}

Data are presented as number (\%). TR = Tubal resection; PS = primary school.

${ }^{a}$ Including Shan, Myanmar, Karen, Muser, etc.

Table 2. Predictors for using long-acting reversible contraception

\begin{tabular}{|c|c|c|c|c|}
\hline Variables & Category & Women & $\mathrm{p}$ value $^{\mathrm{a}}$ & $\begin{array}{l}\text { Multivariate analysis, } \\
\text { odds ratio }(95 \% \mathrm{CI})\end{array}$ \\
\hline Age & $\begin{array}{l}\leq 24 \text { years } \\
>24 \text { years }\end{array}$ & $\begin{array}{l}148 / 247(59.9 \%) \\
247 / 537(45.9 \%)\end{array}$ & $<0.001$ & $1.74(1.28-2.37)$ \\
\hline Formal education & $\begin{array}{l}\leq \text { primary school } \\
>\text { primary school }\end{array}$ & $\begin{array}{r}99 / 158(62.66 \%) \\
296 / 626(47.28 \%)\end{array}$ & 0.001 & $1.85(1.29-2.66)$ \\
\hline Ethnicity & $\begin{array}{l}\text { Minority } \\
\text { Thai }\end{array}$ & $\begin{array}{r}57 / 89(64.04 \%) \\
338 / 695(48.63 \%)\end{array}$ & 0.006 & $1.26(0.71-2.23)$ \\
\hline Living children & $\begin{array}{l}>2 \\
\leq 2\end{array}$ & $\begin{array}{r}13 / 20(65.0 \%) \\
382 / 764(50.0 \%)\end{array}$ & 0.185 & $0.58(0.23-1.50)$ \\
\hline
\end{tabular}

This analysis was based on 784 women who used reversible contraceptions.

a Univariate analysis. ${ }^{\mathrm{b}}$ Including Shan, Myanmar, Karen, Muser, etc.

POPs due to irregular bleeding is well known [11]. The POP users therefore need to be closely monitored to determine their compliance with medication regimen.

The high acceptance rate (50.4\%) of LARC could be due to its several advantages over other reversible methods including very high effectiveness, virtually no patient compliance problems and reversibility. These benefits are of importance to developing countries and should be highlighted to all postpartum women [12]. This view is supported by a recent American College of Obstetrics and Gynecology Committee Opinion that suggested that providers offer LARC, IUD and implant in particular, as methods of first choice for most women [13].

Interestingly, significant independent factors influencing the acceptance of LARC in the present study were age and education level. Postpartum women with little or no formal education and those women aged $\leq 24$ years were more likely to use LARC. This is important because 
of the fact that both young women and less educated women are at risk for contraceptive failure and unintended pregnancy $[12,14]$. The providers may need to make an increased effort to offer LARC to these women.

Although the acceptance rate of LARC among women using reversible contraception (50.4\%) in the present study was higher than previously reported $[6,7,9]$, attention must be drawn to the fact that almost all of LARC used in this study was DMPA, since the acceptance rate of IUD and implant was $<1 \%$. The low acceptance rate of IUD and implant in this study is similar to that reported in the recent Thailand Family Planning Report which demonstrated that the use rates of IUD and implant in general practices were extremely low at only 3.1 and $1.5 \%$, respectively [15]. Hence, designing and implementing effective interventions for promoting IUD and implant use in Thailand is crucial and merits future research.

Approximately $14.4 \%$ of women undergoing immediate postpartum tubal resection in the present study were $\leq 24$ years of age. Although the choices of contraceptive use should freely depend on couple's decision, sterilization in fact would be a most cost-effective choice for women who do not wish to retain their future fertility anymore [16]. However, available data suggest that women sterilized at a young age are more likely to request a surgical reversal or other assisted reproductive procedures later in life [17]. Apart from the information regarding its irreversibility, risks, benefits, and failure rates associated with tubal resection, information on LARC, particularly IUD, should be routinely offered to all women considering sterilization as an alternative option. This is particularly important in young women since LARC has high and long-term effectiveness, but is reversible.

Having unprotected sexual intercourse before attending postpartum clinic is not uncommon as seen in this study where $14 \%$ of women had vaginal intercourse before the 6-week postpartum visit. The immediate provision of contraception, i.e. postplacental IUD insertion, DMPA, and implant after delivery has been proposed as alternative options because these methods do not only eliminate risks of unintended pregnancy in women who wish to resume sexual activity early but also enhances the contraceptive coverage as much as possible since the high default rate from postpartum family planning appointment has been reported [9]. Although using IUD and long-acting progestin in the early postpartum period is associated with a higher expulsion rate and spotting, respectively, the benefits generally outweigh the risks [18].

As mentioned earlier, LARC, especially IUD, should be discussed with all women considering sterilization or requiring immediate postpartum contraception. This would be possible if family planning advice could be initiated antenatally. Concomitant family planning services given prior to delivery and during the immediate postpartum period have been proposed to give couples more time to carefully consider their reproductive options than those services given only in postpartum visit $[19,20]$. However, the frequency of antenatal counseling for family planning varies widely among institutions. The type of health care provider, number of antenatal visits and patient's primary language have been reported to be factors influencing the provision of antenatal contraceptive counseling [19].

Due to the widespread use of breastfeeding, OCPs are rarely used (5\%) consistent with the suggestions of the 2009 Postnatal Care Guidelines of the Faculty of Sexual and Reproductive Healthcare, Royal College of Obstetricians and Gynaecology, which state that OCPs should be avoided in breastfeeding mothers [18]. With various effective contraception methods that have no significant effects on breastfeeding available, indications for use of OCPs postpartally are limited. However, due to insufficient data the authors cannot explain the reasons for prescribing OCPs to postpartum women.

Given the high burden of unintended pregnancy and human immunodeficiency virus infection, particularly in developing countries, promoting condoms in addition to other contraceptive methods, the so-called dual contraception, should be considered. In this study, no postpartum women admitted to using dual contraception. Therefore, further investigations to find out the reason for low acceptance rate of dual contraception use and intervention to promoting this method are warranted.

The limitations of this study include a lack of some relevant data including intended spacing time, marriage status, level of income, previous contraceptive use, and concomitant health-related problems. Additionally, due to the retrospective design of the study, other information, i.e. duration of breastfeeding, compliance of POP users, contraception practice after completion of breastfeeding and reasons for the low acceptance rate of IUD, implantation, and dual contraception, was not available.

\section{Conclusion}

The acceptance rate of contraception in this study was high. However, the following issues need to be evaluated: compliance of women using POPs, awareness of LARC as alternative options in women considering sterilization, and interventions to promote the use of IUD and implant. 


\section{References}

1 Okonofua F: Abortion and maternal mortality in the developing world. J Obstet Gynaecol Can 2006;28:974-979.

2 Conde-Agudelo A, Belizán JM, Breman R, Brockman SC, Rosas-Bermudez A: Effect of the interpregnancy interval after an abortion on maternal and perinatal health in Latin America. Int J Gynaecol Obstet 2005; 89:S34-S40.

3 Kovavisarach E, Chairaj S, Tosang K, Asavapiriyanont S, Chotigeat U: Outcome of teenage pregnancy in Rajavithi hospital. J Med Assoc Thai 2010;93:1-8.

-4 Hsieh TT, Liou JD, Hsu JJ, Lo LM, Chen SF, Hung TH: Advanced maternal age and adverse perinatal outcomes in an Asian population. Eur J Obstet Gynecol Reprod Biol 2010;148:21-26.

$\checkmark 5$ Jansen WH 2nd: Existing demand for birth spacing in developing countries: perspectives from household survey data. Int J Gynaecol Obstet 2005;89:S50-S60.

$\checkmark 6$ Adegbola O, Okunowo A: Intended postpartum contraceptive use among pregnant and puerperal women at a university teaching hospital. Arch Gynecol Obstet 2009;280: 987-992.

7 Engin-Ustün Y, Ustün Y, Cetin F, Meydanli MM, Kafkasli A, Sezgin B: Effect of postpartum counseling on postpartum contraceptive use. Arch Gynecol Obstet 2007;275:429432 .
8 Mohamed SA, Kamel MA, Shaaban OM, Salem HT: Acceptability for the use of postpartum intrauterine contraceptive devices: Assiut experience. Med Princ Pract 2003;12: $170-175$

-9 Ogburn JA, Espey E, Stonehocker J: Barriers to intrauterine device insertion in postpartum women. Contraception 2005;72:426429.

10 FFPRHC Guidance Emergency contraception: Faculty of family planning and reproductive health care clinical effectiveness unit. J Fam Plann Reprod Health Care 2006 32:121-128.

11 Grimes DA, Lopez LM, O’Brien PA, Raymond EG: Progestin-only pills for contraception. Cochrane Database Syst Rev 2010; 1:CD007541.

12 Ozalp S, Yalcin OT, Hassa H, Erbay B, Dalan $\mathrm{N}$ : Factors affecting the contraceptive choice in a developing country. Int J Gynaecol Obstet 1999;65:53-57.

13 American College of Obstetricians and Gynecologists Committee on Gynecologic Practice, Long-Acting Reversible Contraception Working Group: ACOG Committee Opinion No. 450: Increasing use of contraceptive implants and intrauterine devices to reduce unintended pregnancy. Obstet Gynecol 2009;114:1434-1438.

14 Whitaker AK, Johnson LM, Harwood B, Chiappetta L, Creinin MD, Gold MA: Adolescent and young adult women's knowledge of and attitudes toward the intrauterine device. Contraception 2008;78:211-217.
15 Thailand and family planning: an overview. http://www.searo.who.int/linkfiles/family_planning_fact_sheets_thailand.pdf; accessed 14 March 2010

>16 Mavranezouli I, LARC G, Development Group: The cost-effectiveness of long-acting reversible contraceptive methods in the UK: analysis based on a decision-analytic model developed for a national institute for health and clinical excellence (NICE) clinical practice guideline. Hum Reprod 2008;23:13381345

17 Curtis KM, Mohllajee AP, Peterson HB: Regret following female sterilization at a young age: a systematic review. Contraception 2006;73:205-210.

18 Faculty of Sexual \& Reproductive Healthcare Clinical Guidance. Postnatal Sexual and Reproductive Health 2009. http://www. ffprhc.org.uk/admin/uploads/ceuguidancepostnatal09.pdf; accessed 14 March 2010.

19 Day T, Raker CA, Boardman LA: Factors associated with the provision of antenatal contraceptive counseling. Contraception 2008; 78:294-299.

20 Rawal N, Das G, Kishen M: Assessment of contraceptive services in a maternity unit of a district general hospital in the UK. J Obstet Gynaecol 2005;25:179-181. 